EM DEFESA DA PESQUISA

Seção de artigos livres 
- O direito à educação e as possibilidades de ressignificação: um relato de experiência com pessoas em situação de rua

\section{Edmarcius Carvalho Novaes, Sandra Aparecida Barbosa Souza,} Wanderson Pereira 


\title{
O direito à educação e as possibilidades de ressignificação: um relato de experiência com pessoas em situação de rua
}

\author{
The right to education and the possibilities of
}

resignification: an experience report with people in

street situation

\section{Edmarcius Carvalho Novaes ${ }^{1}$ Sandra Aparecida Barbosa Souza² Wanderson Pereira ${ }^{3}$}

Resumo: O presente artigo tem por objetivo compreender como a educação se constitui em um direito que contribui nos processos

1 Aluno do Doutorado Interdisciplinar em Ciências Humanas da Universidade Federal de Santa Catarina, na área de concentração em Estudos de Gênero, e membro do Núcleo de Identidades de Gênero e Subjetividades (NIGS/UFSC). Mestre em Gestão Integrada do Território (UNIVALE, 2016). Especialista em Docência para o Ensino Superior (IMES, 2011), Educação e Inclusão - Linha de Formação: Libras (FAEL, 2013), Gênero e Diversidade na Escola (UFMG, 2016), Direito Público (UNIDERP, 2011) e em Gestão Pública (UFOP, 2013), além de MBA em Administração Pública e Gestão de Cidades (UNIDERP, 2011). É Bacharel em Direito (FADIVALE, 2007) e Licenciando em Filosofia. Professor e pesquisador na UNIVALE - Universidade do Vale do Rio Doce, onde leciona e atua em quatro projetos de pesquisa e extensão vinculados ao NIEDS - Núcleo Interdisciplinar de Educação, Direito e Saúde. E-mail: edmarcius@hotmail.com

2 Licenciada em Pedagogia pela Universidade Vale do Rio Doce (2017), pós-graduada em Gestão Educacional, Psicopedagogia Clínica e Institucional, Educação Inclusiva e Especial e Alfabetização, Letramento e Educação Infantil pelo Instituto Mineiro de Ensino Superior (2018). Professora Regente de Turma na Creche Manuela Domingas de Castro, em Governador Valadares.

3 Graduado em Pedagogia pela Universidade Vale do Rio Doce - UNIVALE (2017). 
de ressignificação de vida da população em situação de rua. Assim, analisa a relação entre a execução de políticas de atendimento à esse grupo e as propostas pedagógicas da Educação Popular de Rua, na realidade da cidade mineira de Governador Valadares. Trata-se de uma pesquisa qualitativa, com a realização de revisão bibliográfica e documental, e relato de experiência sobre intervenção socioeducativa a partir das contribuições de Paulo Freire. Resulta-se na comprovação de uma organização nacional da política de atendimento ao referido público, que tem sido implantada de forma sistêmica considerando as demandas específicas de cada localidade, mas que no entanto carente de profissionais capacitados para uma melhor atuação. Conclui-se que a educação é um direito que deve dialogar com as demais políticas públicas destinadas à população de rua, numa perspectiva que fomente a construção de novas identidades e de pertencimento à sociedade.

Palavras-chaves: Paulo Freire - Direito à educação - Pessoa em situação de rua.

Abstract: This article aims to understand how education is a right that contributes to the processes of resignification of life of the homeless population. Thus, it analyzes the relation between the execution of policies of attendance to this group and the pedagogical proposals of Popular Street Education, from the mining city of Governador Valadares. This is a qualitative research, with a bibliographic and documentary review, and an experience report on socio-educational intervention from the contributions of Paulo Freire. These results in the proving of a national organization of the policy of attendance to the referred public, which has been implemented in a systemic way based on the specific demands of each locality, but which, however, lacks professionals capable of performing better. It is concluded that education is a right that should dialogue with other public policies aimed at the homeless, in a perspective that fosters the construction of new identities and belonging to society.

Keywords: Paulo Freire - Right to education - Homeless person. 


\section{INTRODUÇÃO}

O avanço da globalização provocou diversas consequências, e dentre as quais a desigualdade social ganha destaque. Numa perspectiva marxista, a distribuição de bens de forma desigual e o desrespeito às diferenças advém do processo capitalista (MARX, 1988) e do pensamento globalizado (HALL, 2006). Em países em desenvolvimento como Brasil, é notável o fortalecimento de posicionamentos políticos/ ideológicos neoliberais, o que impede a constituição de um estado de bem-estar social (BORTOLIM, 2014). De acordo com Vieira (1992), diversos são os problemas que evidenciam a potência do sistema socioeconômico atual em negar certos grupos de pessoas, perdendo a humanização e menosprezando-os.

Entre estes, vislumbra-se a população em situação de rua, compreendida como

(...) grupo populacional heterogêneo, composto por pessoas com diferentes realidades, mas que têm em comum a condição de pobreza absoluta e a falta de pertencimento à sociedade formal. São homens, mulheres, jovens, famílias inteiras, grupos, que têm em sua trajetória a referência de ter realizado alguma atividade laboral, que foi importante na constituição de suas identidades sociais. Com o tempo, algum infortúnio atingiu suas vidas, seja a perda do emprego, seja o rompimento de algum laço afetivo, fazendo com que aos poucos fossem perdendo a perspectiva de projeto de vida, passando a utilizar o espaço da rua como sobrevivência e moradia (COSTA, 2005, p. 3).

Caracterizada pelo fato de sobreviver nas ruas das médias e grandes cidades, utilizando-as, circunstancialmente ou permanentemente como sua moradia, apresenta especificidades de gênero, relações étnico-raciais, geracionais e de deficiências - além de, geralmente, vínculos familiares enfraquecidos, que nas últimas décadas, tem crescido no território brasileiro, segundo dados oficiais (BRASIL, 2005).

Neste contexto, as legislações existentes surgiram com o intuito de oferecer serviços e programas socioassistenciais, a fim de garantir 
padrões éticos e dignos com os direitos de cidadania. As possibilidades de superação vislumbradas à população em situação de rua são diversificadas e visam proporcionar-lhes voz ativa para tomadas de decisões, com respeito a autonomia e emancipação (ALMEIDA, 2012).

Criar alternativas para a realidade desse público é um processo desafiador, levando em conta as vulnerabilidades em que se encontram. Porém, algumas políticas têm tido progresso e apontam que a educação (sobretudo, a popular de rua) fomenta a ressignificação de vida dessa população. Brandão (2006) conceitua a educação popular como aquela que não está institucionalizada, que ocorre dentro e com os grupos populares, com enfoque na realidade e na perspectiva histórica do público alvo.

Segundo Pini (2006) a importância da educação popular para as pessoas em situação de rua consiste no envolvimento desses cidadãos no processo de construção do exercício da cidadania ativa, ocupação do espaço público e luta pelos seus direitos humanos. Assim, a educação é tida como de extrema valia, pois não se restringe à transmissão de conhecimentos técnicos, mas visa valorizar os princípios individuais.

Este trabalho reflete sobre a educação como um direito, cujo efeito possibilita a ressignificação da pessoa em situação de rua. Problematiza-se como a educação popular de rua tem contribuído para os processos de ressignificação de vida desta população, a partir de vivências pedagógicas ocorridas na cidade mineira de Governador Valadares.

A metodologia usada é a revisão bibliográfica e documental, a partir de uma pesquisa exploratória e de campo. O trabalho encontra-se estruturado com a proposta de analisar a relação entre as políticas de atendimento à pessoa em situação de rua e as possibilidades de educação (popular de rua) como um direito. Para tanto, se propõe compreender como se dá a Política Nacional de Atendimento à Pessoa em Situação de rua, identificar como a Educação Popular de Rua possibilita a projeção de futuro deste público, e apresentar as aprendizagens adquiridas na vivência de estágio em educação não-escolar ${ }^{4}$ em um órgão público na cidade de Governador Valadares.

4 Trata-se de uma modalidade de estágio obrigatório curricular existente na matriz pedagógica do Curso de Pedagogia da Universidade Vale do Rio Doce, com o intuito de 


\section{A POLÍTICA NACIONAL DA PESSOA EM SITUAÇÃO DE RUA}

A Política Nacional da Pessoa em Situação de Rua (2010) estabelece diretrizes que propõe sua reabilitação junto à familiares e comunidade, gerando acesso a oportunidade e ao desenvolvimento social pleno (levando em conta as vivências do espaço público da rua) e aos direitos garantidos aos cidadãos.

Historicamente $^{5}$, no ano de 1993, o Congresso Nacional aprovou a Lei Orgânica da Assistência Social (LOAS) ${ }^{6}$, que regulamentou os artigos 203 e 204 da Constituição Federal, "(...) reconhecendo a Assistência Social como política pública, direito do cidadão e dever do Estado, além de garantir a universalização dos direitos sociais".

Logo após a LOAS, incluiu-se a lei de obrigatoriedade de criação de programas de amparo à população em situação de rua. Com a nova legislação (n 11.258 , de 30 de dezembro de 2005), o poder público municipal passou a ter a função de manter programas e serviços de atenção à população de rua, garantindo os direitos de cidadania a nível local. A necessidade de sua implantação deve-se às diversas denúncias de práticas de massacres, roubos, agressão verbal e/ou física, constrangimentos.

No artigo $7^{\circ}$ do Decreto $n^{\circ}$. 7053/2009, que institui a Política Nacional da Pessoa em Situação de Rua, são descritos os seguintes objetivos da atuação governamental:

contribuir na formação discente para a atuação, na docência e na gestão, em espaços não-escolares, a partir do marco teórico epistemológico fenomenológico-existencial da Educação Social (PINEL, et. al. 2012), com base em Freire (1996, 2013).

5 Registra-se que a aprovação da Política Nacional para a Pessoa em Situação de Rua foi precedida de diversas manifestações sociais, organizada pela sociedade civil, tais como o Fórum Nacional de Estudos sobre a População de Rua em 1993; o Grito dos Excluídos, em 1995; o $1^{\circ}$ Congresso Nacional de Catadores, a $1^{a}$ Marcha do Povo de Rua, em Brasília, no ano de 1996, dentre outros.

$6 \quad$ Lei Federal $n^{\circ}$ 8.742, de 7 de dezembro de 1993. 
I - assegurar o acesso amplo, simplificado e seguro aos serviços e programas que integram as políticas públicas de saúde, educação, previdência, assistência social, moradia, segurança, cultura, esporte, lazer, trabalho e renda;

II - garantir a formação e capacitação permanente de profissionais e gestores para atuação no desenvolvimento de políticas públicas intersetoriais, transversais e intergovernamentais direcionadas às pessoas em situação de rua;

III - instituir a contagem oficial da população em situação de rua; IV - produzir, sistematizar e disseminar dados e indicadores sociais, econômicos e culturais sobre a rede existente de cobertura de serviços públicos à população em situação de rua;

$\mathrm{V}$ - desenvolver ações educativas permanentes que contribuam para a formação de cultura de respeito, ética e solidariedade entre a população em situação de rua e os demais grupos sociais, de modo a resguardar a observância aos direitos humanos;

VI - incentivar a pesquisa, produção e divulgação de conhecimentos sobre a população em situação de rua, contemplando a diversidade humana em toda a sua amplitude étnico-racial, sexual, de gênero e geracional, nas diversas áreas do conhecimento;

VII - implantar centros de defesa dos direitos humanos para a população em situação de rua;

VIII - incentivar a criação, divulgação e disponibilização de canais de comunicação para o recebimento de denúncias de violência contra a população em situação de rua, bem como de sugestões para o aperfeiçoamento e melhoria das políticas públicas voltadas para este segmento;

IX - proporcionar o acesso das pessoas em situação de rua aos benefícios previdenciários e assistenciais e aos programas de transferência de renda, na forma da legislação específica;

$X$ - criar meios de articulação entre o Sistema Único de Assistência Social e o Sistema Único de Saúde para qualificar a oferta de serviços;

XI - adotar padrão básico de qualidade, segurança e conforto na estruturação e reestruturação dos serviços de acolhimento temporários, de acordo com o disposto no art. 80;

XII - implementar centros de referência especializados para atendimento da população em situação de rua, no âmbito da proteção social especial do Sistema Único de Assistência Social; 


\begin{abstract}
XIII - implementar ações de segurança alimentar e nutricional suficientes para proporcionar acesso permanente à alimentação pela população em situação de rua à alimentação, com qualidade; e

XIV - disponibilizar programas de qualificação profissional para as pessoas em situação de rua, com o objetivo de propiciar o seu acesso ao mercado de trabalho. (BRASIL, 2009)
\end{abstract}

De acordo com a referida política, são os enfraquecimentos de vínculos familiares que tendem a fazer com que os indivíduos se tornem pessoas em situação de vulnerabilidades. O texto legal surge com o intuito de fomentar ações para o restabelecimento desses laços familiares. Salienta-se que a Declaração Universal dos Direitos Humanos (1948) já reconhecia e assegurava esses direitos, afirmando que todas as pessoas nascem livres e iguais, e formam a comunidade humana - homem ou mulher, negro ou branco, rico ou pobre, adepto (ou não) de qualquer religião, e nascido em qualquer lugar do mundo - tendo o direito à liberdade e à segurança pessoal.

A Constituição Federal, em seu artigo $5^{\circ}$, dispõe sobre a igualdade à todos os cidadãos perante à lei e sobre a não violação do direito à vida, à liberdade, à segurança e à propriedade. No artigo $6^{\circ}$, lê-se que "são direitos sociais, a educação, a saúde, o trabalho, a moradia, o lazer, a segurança, a previdência social, a proteção à maternidade e à infância, a assistência aos desamparados" (BRASIL, 1988).

Porém, somente no ano de 2009, quando entrou em vigência o decreto supracitado, que regulamentou a Política Nacional para a População em Situação de Rua, que essa população, de fato, se tornou foco de políticas públicas no campo legal. $O$ decreto tem por objetivo assegurar os direitos sociais deste grupo, criando condições para promover a garantia dos seus direitos fundamentais, da sua autonomia, integração e participação efetiva na sociedade.

Para tanto, estabelece como princípios a igualdade e equidade; respeito à dignidade da pessoa humana; direito à convivência familiar e comunitária; valorização e respeito à vida e a cidadania; atendimento humanizado e universalizado; respeito às condições sociais e diferenças de origem, raça, idade nacionalidade, gênero, orientação sexual e 
religiosa, com atenção às pessoas com deficiência. As diretrizes que pautam as políticas para as pessoas em situação de rua, segundo o Decreto em seu artigo $6^{\circ}$, são:

I - promoção dos direitos civis, políticos, econômicos, sociais, culturais e ambientais;

II - responsabilidade do poder público pela sua elaboração e financiamento;

III - articulação das políticas públicas federais, estaduais, municipais e do Distrito Federal;

IV - integração das políticas públicas em cada nível de governo;

V - integração dos esforços do poder público e da sociedade civil para sua execução;

VI - participação da sociedade civil, por meio de entidades, fóruns e organizações da população em situação de rua, na elaboração, acompanhamento e monitoramento das políticas públicas;

VII - incentivo e apoio à organização da população em situação de rua e à sua participação nas diversas instâncias de formulação, controle social, monitoramento e avaliação das políticas públicas; VIII - respeito às singularidades de cada território e ao aproveitamento das potencialidades e recursos locais e regionais na elaboração, desenvolvimento, acompanhamento e monitoramento das políticas públicas;

IX - implantação e ampliação das ações educativas destinadas à superação do preconceito, e de capacitação dos servidores públicos para melhoria da qualidade e respeito no atendimento deste grupo populacional; e

$X$ - democratização do acesso e fruição dos espaços e serviços públicos. (BRASIL, 2009)

Segundo Pereira e Santos (2013), outro avanço histórico foi aprovação da Resolução no 109, de 11 de novembro de 2009, do Conselho Nacional de Assistência Social. Trata-se da Tipificação Nacional de Serviços Socioassistenciais, considerada essencial para a efetivação de serviços direcionados à população em situação de rua no Sistema Único de Assistência Social - SUAS, que passou a ter garantido serviços tipificados, dependendo da demanda ou da violação de direito vivenciadas. 
Destacam-se quatro serviços que possuem exclusividade no atendimento a este público: Serviço Especializado em Abordagem Social; Serviço Especializado para Pessoas em Situação de Rua; Serviço de Acolhimento Institucional; Serviço de Acolhimento em República. Tais serviços devem disponibilizar, segundo a normativa supracitada, programas, projetos e assistência de caráter especializado, contribuindo para a proteção social de famílias e pessoas em situações de risco.

Pereira e Santos (2013) afirmam que o serviço especializado em abordagem social representa um importante recurso para a identificação de pessoas em situação de rua, pois oferece atendimento no próprio contexto de vivência, realizando intervenções necessárias mais imediatas e a vinculação gradativa aos serviços socioassistenciais.

O serviço especializado para pessoas em situação de rua se materializa em um atendimento especializado, visando à construção do processo de saída das ruas e o alcance de referências como cidadãos de direitos. Por sua vez, os serviços de acolhimento têm como intuito garantir às pessoas que usam as ruas como espaço de moradia e/ ou sobrevivência um acolhimento temporário, possibilitando desenvolver sua independência, autonomia e o autocuidado. Já o acolhimento, de caráter institucional, se caracteriza por ser um espaço semelhante a uma residência, com o objetivo de ofertar acolhimento imediato e emergencial. Por fim, o acolhimento em república consiste em acolher pessoas adultas com vivência de rua em fase de reinserção social, ou seja, que estejam em fase de reestabelecimento dos vínculos sociais. Nota-se que o acolhimento institucional é para pessoas e famílias em situação de rua; e o acolhimento em república é para pessoas em processo de saída de situação de rua.

No artigo $8^{\circ}$ do referido decreto, há a afirmativa que é de responsabilidade do Ministério do Desenvolvimento Social e Combate à Fome ${ }^{7}$, por intermédio da Secretaria Nacional de Assistência Social, promover a reestruturação e a ampliação dessa rede de acolhimento a partir

7 Em 2016, ainda na gestão do ex-presidente Michel Temer, passou a ser denominado Ministério de Desenvolvimento Social e Agrário. Atualmente, a Secretaria Nacional de Assistência Social encontra-se vinculada no Ministério da Cidadania. 
da transferência de recursos aos Municípios, Estados e Distrito Federal. Tais áreas de acolhimento temporário devem ser reestruturadas e ampliadas, a fim de incentivar pessoas em situação de rua a utilizarem o equipamento; prospectando a possibilidade de participação em programas de moradia popular promovidos pelos Governos Federal, Estaduais, Municipais.

De acordo com a Portaria $n^{\circ} 843$, de 28 de dezembro de 2010, do Ministério de Desenvolvimento Social e Combate à Fome, a proteção social especial e os quatro serviços acima citados destinados às pessoas em situação de rua, são referenciados em dois tipos de equipamentos públicos: Centro de Referência Especializado para População em Situação de Rua (Centro POP), Centro de Referência Especializado de Assistência Social (CREAS).

Regulamentado também pelo no Decreto $n^{\circ} 7.053 / 2009$, o Centro de Referência Especializado para População em Situação de Rua, comumente conhecido como "Centro Pop" (MDS, 2011) é um espaço para atendimento específico à esta população, e objetiva proporcionar o convívio e interação social, desenvolver as relações de afetividade, solidariedade e respeito. Os serviços nessa unidade procuram gerar vivências para o alcance da autonomia, estimulando, a mobilização, a organização e a participação social dos indivíduos.

A referida normativa ainda descreve os aspectos estruturais que 0 equipamento público deve apresentar: padrão básico de qualidade, segurança e conforto, regras de funcionamento e convivência, acessibilidade, salubridade e distribuição geográfica das unidades de acolhimento nas áreas urbanas. Conforme a Tipificação, o Centro POP além de oferecer o serviço especializado à estas pessoas também pode ofertar o serviço especializado em abordagem social. Porém, nestes casos, necessita-se um bom gerenciamento, considerando a necessidade de interação entre os dois serviços oferecidos na mesma unidade; caso necessário, deve-se redimensionar os recursos humanos e sua respectiva capacitação, assegurando a qualidade de ambos os serviços.

A Portaria $n^{\circ} 843$, de 28 de dezembro 2010, define o CREAS como um centro especializado de assistência social, que consiste 
em ofertar orientação específica e continuada a quaisquer indivíduos que tenham seus direitos violados (não se restringe apenas às pessoas em situação de rua). Envolve um conjunto de profissionais e processos de trabalho que devem oferecer apoio especializado, e objetiva resgatar os direitos violados, potencializando sua capacidade de proteção aos seus membros.

As autoras Pereira e Santos (2013) descrevem que em municípios cuja demanda for pequena e não se justificar a uma unidade do Centro POP, a oferta do serviço especializado às pessoas em situação de rua deve ocorrer no CREAS. Nesse caso, o CREAS não substitui o serviço prestado pelo Centro POP, no entanto, oferecer serviços específicos com intuito de prevenir algum agravamento de risco pessoal e social, possibilitando a construção do processo de saída das ruas, com intervenções em rede.

É importante destacar que o CREAS e o Centro POP são espaços totalmente distintos, devendo funcionar em unidades diferentes. Cada espaço tem sua singularidade e intencionalidade, seu tipo de organização, infraestrutura, serviços ofertados e equipe especializada.Para tanto, cabe garantir a necessidade da intersetorialidade na execução desses serviços, entendida como uma maneira de executar serviços, articulando saberes e fazeres, em todas as áreas da gestão, seja na avaliação, na implementação ou no planejamento (PEREIRA \& SANTOS, 2013). É importante para se construir uma prática social baseada na realidade da população em situação de rua, com atenção especial, às possibilidades educativas.

\section{O DIREITO À EDUCAÇÃO PARA A POPULAÇÃO EM SITUAÇÃO DE RUA}

A Pedagogia Social surgiu no Brasil como um caminho para pensar a intervenção educacional para públicos em vulnerabilidades, e cria instrumentos que auxiliam na compreensão dos saberes produzidos e adquiridos, inclusive na rua (PINEL et. al., 2012). Basicamente, a Educação Popular, enquanto possibilidade de práticas de uma Peda- 
gogia Social, consiste em uma metodologia que valoriza mais do que o simples saber acadêmico, os saberes prévios e as realidades culturais vivenciadas pelos alunos em seus processos de aprendizagem.

Tradicionalmente, no Brasil, a educação, muitas vezes, valoriza o sistema formal de ensino, não preocupando-se com a educação que ocorre para além dos muros da escola, ou seja, em outros âmbitos da vida humana. Diferentemente, a Educação Popular de Rua contribui para desenvolver um olhar crítico, de modo a facilitar o desenvolvimento em comunidade, estimulando o diálogo e uma melhor leitura da realidade social, política e econômica. De igual modo, possibilita a saída do educando das ruas, com a (re)inserção na sociedade, de forma a exercer adequadamente sua cidadania.

De acordo com Petrus (2003), a educação tem como objetivo capacitar o indivíduo para viver em sociedade. A educação não é uma solução, mas acontece como uma intervenção, agindo de forma hábil, flexível e dinâmica. No campo normativo, o artigo 205 da Constituição Federal de 1988 descreve que a educação é um direito de todos. O artigo $1^{\circ}$ da Lei de Diretrizes Básicas da Educação Nacional (BRASIL, 1996) amplia o conceito esse direito à educação para além dos espaços da escola, enfatizando que a educação também acontece na família, na convivência humana, nos movimentos sociais: portanto, em toda parte, seja de forma intencional ou não.

A educação como um direito, para Paulo Freire (2000), se dá em razão da necessidade de a educação despertar a consciência humana e a capacidade crítica em relação às mudanças na realidade, seus aspectos culturais e históricos; portanto, sua necessidade de fomentar uma postura ativa diante dos fatos:

[...] na medida em que nos tornamos capazes de transformar o mundo, de dar nome às coisas, de perceber, de inteligir, de decidir, de escolher, de valorar, de, finalmente, eticizar o mundo, o nosso mover-nos nele e na história vem envolvendo necessariamente sonhos por cuja realização nos batemos. Daí então, que a nossa presença no mundo, implicando escolha e decisão, não seja uma presença neutra (FREIRE, 2000, p. 17). 
Atrelada à educação, há a necessidade de se efetivar a proteção social. Segundo Machado (2014), é notável a necessidade de gerar benefícios, projetos, programas e serviços de Assistência Social, com o objetivo de proporcionar atenção integral à população em situação de rua, que geralmente, tem uma vida marcada pela negação de seus direitos. Tal negação se dá, em muitos casos, com a prática da higienização social (MACHADO, 2014), termo utilizado para referir-se à eliminação de componentes sociais indesejáveis, o que exemplifica o sentimento de algumas camadas sociais em relação às pessoas em situação de rua.

A Educação Popular de Rua, como um direito que exige o diálogo entre as políticas públicas, surge como enfrentamento para se romper uma lógica construída historicamente que é segregacionista e higienista, em que os indivíduos não são tratados com dignidade e não possuem direitos garantidos, sendo imprescindível entender as dificuldades e possibilidades de retorno/continuação da escolarização desse grupo.

Almeida (2012), em pesquisa realizada em São Carlos/SP, destaca alguns obstáculos percebidos perante o contato com pessoas em situação de rua em relação à sua (re)inserção no âmbito escolar. Relataram a falta de documentação civil, a ausência de condições materiais para estar em ambientes escolares (roupas, tênis, etc.), o fato da escola valorizar mais os saberes acadêmicos e de estarem fora da escola há muito tempo, o modelo escolar formal que é rígido e disciplinador, além de questões de orientação sexual, dependência química, dentre outras.

A autora apresenta possibilidades de superação existentes, como a atuação de instituições e pessoas que incentivem e facilitem o resgate da documentação, a prestação de serviços de assistência social, que motivem o retorno e a continuação de processos de escolarização, a necessidade de superação do preconceito, de oportunidades de trabalho, emprego e renda, dentre outros aspectos. Almeida (2012) ainda aponta que ao ser inserida no âmbito escolar, essa população consegue adquirir voz ativa perante as tomadas de decisões que dizem respeito a sua autonomia e emancipação. 
Paiva (2010) afirma a necessidade de perceber o mundo à sua volta, a importância de investigar tudo aquilo que fica escondido na sociedade, e que fazem as pessoas em situação de rua viverem num mundo tão distante daqueles que buscam ajudá-los. Aponta que mais que uma ajuda, o educador popular de rua é um profissional criador de espaços de escuta, percepção, sentido, sem horário específico, sem moralismos e julgamentos, voltado apenas para o protagonista da história, o educando. Galeano (2009) por sua vez, enfatiza a importância de perceber, identificar e recuperar essas vozes perdidas - que muitos não oferecem nem se quer um pouco de seu tempo.

Neste sentido, é mister remeter a discussão à Freire (2002), para o qual educação não limita-se somente ao modelo escolar. É certo que tal modelo não deve ser desvalorizado; no entanto, é importante pontuar que não existe uma educação, e sim 'educações' neologismo para apontar o que acontece em diversos espaços, de diversas formas. A diferença entre o professor e o educador social que se pauta na perspectiva freireana, é que aquele valoriza, em muitos casos, mais uma escola que reforça aspectos formais e acadêmicos, enquanto o último valoriza um trabalho em que ensina e ao mesmo tempo aprende, e assim, entende que seu ofício vai além do acadêmico: consiste em uma abordagem de leitura de vida, conforme as vivências de seu educando.

$\mathrm{Na}$ perspectiva freireana, a metodologia do educador social está pautada no diálogo, crítico e criativo, afim de realizar uma abordagem quanto à existência e importância do educando na sociedade. Tal trabalho demanda estar atento a cada palavra, saber ouvir o educando, analisar cada gesto, deixando-o dizer e fazer o mundo. É preciso lembrar que não basta apenas competência técnica, é fundamental a solidariedade humana e compromisso com o educando.

Freire (2002) destaca que ser um educador é uma questão vocacional, pois trata-se de um trabalho de leitura de mundo inserida em um contexto inóspito. Na lógica da Pedagogia Social, esse profissional passa por um processo de reeducação para oferecer um trabalho com qualidade perante às pessoas em situação de rua, pois acredita-se que a transformação social tem base nas potencialidades e saberes 
que esses sujeitos trazem com eles. É a partir delas que é o primeiro passo é dado para um processo pedagógico que valoriza as vivências, da e na rua, e para sua (re)inserção social como um direito.

\section{RESULTADOS ENCONTRADOS EM GOVERNADOR VALADARES}

Segundo dados oficiais (BRASIL, 2009), o perfil da população em situação de rua é marcado por diversas características. Possui em comum a pobreza, os vínculos familiares interrompidos, o desemprego e outros fatores que os levaram à utilizar as ruas como espaço de moradia, seja permanente ou temporariamente. Em uma pesquisa nacional realizada no ano de 2009 com 31.922 pessoas em situação de rua foi possível identificar o perfil destes indivíduos, sendo grande parte do público composta por homens, negros. Foi constatado também que $75 \%$ não sabiam ler e escrever, não haviam completado o ensino fundamental, e 15\% nunca haviam estudado (BRASIL, 2009).

Para compreender a situação em Governador Valadares, no trabalho de coleta de dados sobre as pessoas em situação de rua em Governador Valadares (GOVERNADOR VALADARES, 2016) ${ }^{8}$, houve a colaboração dos técnicos em serviço que possuíam à época os cadastros das pessoas em situação de rua, devido os atendimentos realizados nos equipamentos públicos CREAS, CENTRO POP, Abrigo Noturno, e a instituição conveniada denominada Missão Vida9 .

Segundo os dados apurados, entre maio e em 2016 na cidade, de 123 pessoas em situação de rua, o número de homens predomina-

8 Ressalta-se a necessidade de realização de novos e atuais levantamentos pelos atuais gestores públicos, em todos os níveis (nacional, estaduais e municipais) sobre o perfil e situação deste segmento pesquisado.

9 "Missão Vida" é o primeiro Centro de Recuperação de Mendigos do Brasil, foi fundada em 1983, por Wildo Gomes dos Anjos. Atualmente, a Missão Vida também desenvolve atividades voltadas para a população carente e está presente nos estados da BA, DF e MG. A unidade de Governador Valadares foi fundada em 16 de Janeiro de 2010, e conta desde o princípio com o importante apoio de igrejas da região, tendo inclusive, suas terras cedidas por uma delas. Fonte: <http://www.mvida.org.br/>. Acesso em: 15 de dezembro de 2019. 
va. Os resultados também apontavam que $50 \%$ não possuíam ensino fundamental completo, o que levou ao número de 53\% sem formação profissional, e que desenvolviam atividades laborais autônomas - portanto, fora do mercado de trabalho formal. Ainda, geralmente o período de vivência nas ruas variava de um até trinta e nove anos. $O$ trabalho apresentava também que diversos eram os territórios nos quais a população em situação de rua se abrigava, mas a região que aparecia como maior referência era o Mercado Municipa $\left.\right|^{10}$ e entorno.

Segundo os dados coletados, cerca de $85 \%$ dos indivíduos entrevistados afirmavam que estavam cadastrados em serviços especializados ao público. Desses, 53\% reconheciam o Centro POP como instituição de maior referência para o acesso aos serviços de Assistência Social; outros $27 \%$ tinham como referência a instituição "Missão Vida"; e apenas 16\%, o Abrigo Noturno. Apesar da maioria dessa parcela da população ser cadastrada nessas organizações de serviços especializadas, apenas $26 \%$ utilizavam as dependências do Abrigo Noturno. Ressalta-se que $61 \%$ diziam ter familiares no município de Governador Valadares.

Também em 2016, ao realizamos ${ }^{11}$ uma vivência de estágio no Abrigo Noturno ${ }^{12}$ da cidade e que atende às pessoas em situação de rua, surgiu o interesse em trabalhar a proposta freireana da Educação Popular de Rua com o público. A referida instituição era um equipamento público vinculado à Secretaria Municipal de Assistência Social SMAS, e mantida pelo próprio município. Possuía algumas instituições parceiras, com o intuito de suprir algumas necessidades que não eram cobertas pelo poder público.

10 Mercado Municipal de Governador Valadares é tradicional na cidade, inaugurado na década de 1940, localizado na região central do município, e de fácil acesso viário. (BRAGA, 2015).

11 A partir deste momento, utilizaremos a primeira pessoa do plural, para referirmos aos dados registrados na vivência do estágio supervisionado, realizado no primeiro semestre de 2016.

12 Popularmente esta instituição pública é conhecida como Albergue Municipal. 
O acolhimento na modalidade abrigo atende de forma provisória, e tem por finalidade ${ }^{13}$ : acolher e garantir a proteção integral; prevenir situações de negligências, violência; restabelecer vínculos familiares e/ou sociais; possibilitar convivências com a comunidade; promover acesso aos órgãos que oferecem alguns direitos e demais políticas públicas; favorecer, desenvolver e oportunizar momentos para que façam escolhas com autonomia e por último promover o acesso aos programas culturais, lazer, esporte realizados na cidade e que seja do interesse dos acolhidos. A equipe técnica da instituição era composta por coordenador, cozinheiros, agentes sociais, secretária, técnico em manutenção, assistente social e psicólogo.

$\mathrm{Na}$ instituição eram realizados bingos e transmissões de filmes, mas essas duas atividades são realizadas sem caráter educativo e/ou intencionalidade. Outro aspecto observado é que na época da pesquisa, geralmente os profissionais (assistente social e psicólogo) cumpriam carga horária na parte da manhã e os indivíduos entravam na parte da tarde, ou seja, acabavam realizando um trabalho sem atender a real necessidade do público alvo. A falta de recursos, de corpo técnico e até mesmo de gestão relacionados ao planejamento e execução das atividades de cunho educativo, além da falta de materiais, foram alguns dos pontos falhos observados durante o estágio.

O abrigo necessitava de maiores investimentos em sua estrutura física, porém, a equipe de funcionários à época fazia um grande esforço para extinguir as lacunas existentes no local. Um outro problema era a relação da instituição com a vizinhança muito repulsa. Levando em conta que os moradores ao entorno não encontravam-se satisfeitos com sua localização, estes alegavam que a presença de pessoas em situação de rua por perto desvalorizava seus imóveis. Isto se dava porque o horário de recebimento do público era das 16 horas as 19 horas, mas ocorriam situações em que alguns não conseguiam vagas e dormiam nas calçadas das proximidades durante o dia.

13 As informações sobre este equipamento público foram registradas em diário de bordo, durante a realização do referido estágio em educação não-escolar. 
Nessa situação, o educador social pode trabalhar para vislumbrar as potencialidades dos sujeitos e, posteriormente, culminar na solução de problemas. No caso em tela era de extrema relevância o educador conscientizar as pessoas em situação de rua à manter um bom relacionamento com a vizinhança, aproximando o público alvo da sociedade no entorno da instituição.

Segundo Gohn (2004) esse tipo de ação do educador pode desencadear um processo com várias dimensões, como a aprendizagem dos direitos enquanto cidadãos, a capacitação desses indivíduos para o mercado de trabalho, por meio da aprendizagem de habilidades e/ou desenvolvimento de potencialidades, a aprendizagem e exercício de práticas que os capacitam a se organizarem com objetivos comunitários, voltadas para a tomadas de decisões e solução de problemas de seu cotidiano, dentre outros.

Com base nesses entraves encontrados durante a vivência do estágio, planejamos e executamos o projeto de intervenção denominado 'Minha vida em um filme'. O intuito era conscientizar os usuários do equipamento, através de filmes e posteriormente diálogos, sobre suas situações de vulnerabilidade e extrair lições de forma a gerar uma reflexão sobre a condição social, e assim levá-los à construção de projetos de vida (VELHO, 2003), com a saída das ruas.

O projeto surgiu a partir de um intenso trabalho de observação na instituição. As atividades desenvolvidas utilizando filmes já ocorriam naquele espaço, porém sem cunho pedagógico. Por isso, remodelamos o cinema à uma prática educativa e pedagógica, trazendo reflexões sobre a educação social e fazendo-os indagar sobre o estado em que se encontram. O projeto teve duração total de trinta horas, desde o planejamento, execução, monitoramento e avaliação. Para a execução foram realizados três encontros, com duração média de 3 horas cada. Em análise, pudemos perceber certa resistência do público alvo em participar, sobretudo dos diálogos após a exibição dos filmes, o que atribuímos ao fato de estas pessoas já estarem tão inseridas em suas vulnerabilidades que não conseguem se enxergarem saindo dessa situação. No entanto, foi 
possível a conclusão das atividades, havendo uma avaliação positiva da intervenção pelos participantes e pelo público alvo.

O aprendizado adquirido é que a Educação Popular de Rua é um direito social para esses indivíduos, que deve ser garantido de forma processual e contínua. Segundo Freire (2005), a verdadeira educação conscientiza sobre as contradições do mundo, e que impedem o homem de seguir em frente, sendo um método pedagógico de conscientização, que segundo o autor, pode alcançar as últimas fronteiras, ou seja, a educação se constitui como a prática da liberdade.

Educar exige engajamento e um amplo olhar, para assim proporcionar ao sujeito o senso crítico, afim de que se perceba sujeito de direitos. Freire (2013) destaca que um dos piores males é o descaso pela educação pública no Brasil, em que o indiferentismo predomina e o discurso acomodado leva ao cruzamento dos braços, afirmando que não há o que fazer. Vencer esse descaso passa por uma Educação Popular que procura sempre superar aos problemas e desafios da realidade, para aperfeiçoar o sistema educativo e possibilitar a melhora das condições de bem estar social dos educandos.

A ausência de uma educação social para as pessoas em situação de rua como um direito pode levar o indivíduo à desesperança por dias melhores; no entanto, a sua presença apresenta novos caminhos. De acordo com Freire (1996), o ser humano é submetido a obstáculos difíceis de serem superados, principalmente pelas influências de concepções de poder na ideologia neoliberal, em que a ética perversa se funda nas leis do mercado. Dessa forma, a matriz da esperança é a mesma da educabilidade: a prática dos educadores sociais salienta que mudar é difícil, mas é possível.

Através da experiência realizada no estágio notou-se as grandes vulnerabilidades em que as pessoas em situação de rua abordadas estão inseridas. Ao contrário do que se presumia, a maioria possuía uma formação e vivência profissional, além de laços familiares. Dessa forma, tornou-se nítida a vulnerabilidade do ser humano, que em momentos adversos perde a dignidade e o foco da vida, devido ao 
desemprego, vício alcoólico e as drogas, desentendimentos familiares, entre outros fatores.

Portanto, a Educação Popular de Rua, com uma perspectiva libertadora em Paulo Freire (1977) deve ser um direito garantido, para que se combata essa vulnerabilidade através do compromisso com uma educação não-escolar de qualidade, proporcionando a construção do conhecimento e o caminho para a liberdade de exercer seus direitos.

\section{ALGUMAS CONSIDERAÇÕES}

De forma mediata, a problemática das vulnerabilidades das pessoas em situação relaciona-se às questões ideológicas e políticas de caráter neoliberais, quando o Estado negligencia suas atribuições para com aqueles que se encontram à margens dos processos formais de ensino e de trabalho - e portanto, se constituem em não possuidores das condições mínimas de sobrevivência digna e humana.

Nesse sentido, de forma imediata, as razões que contribuem para a situação de rua não estão ligadas apenas com a simples ausência de moradia. Relacionam-se a diversos outros fatores: enfraquecimento de vínculo familiar, desemprego, vício em bebidas alcoólicas e/ou outras drogas, etc.

Com isso, a possibilidade efetiva de saída da rua não se restringe à oferta isolada de moradia, mas sim de um trabalho de socioeducação com qualidade, amparado pelas legislações vigentes e oferecido pelos centros especializados, com foco no resgate de princípios e valores da dignidade da pessoa humana, e com práticas de Educação Popular de Rua.

O avanço nas últimas décadas no que tange as políticas sociais aplicadas à população de rua é visível. As legislações vigentes são conquistas consolidadas em uma ampla rede socioassistencial, de proteção e acesso aos serviços especializados. No entanto, ainda são necessárias muitas ações para se reduzir de fato a desigualdade social

Através da análise da vivência de estágio, verificamos que apenas uma parcela dessa população frequenta, e de forma esporádica, o Abrigo Noturno em Governador Valadares, o que demonstra a insuficiência da infraestrutura frente a demanda existente, e a necessidade 
de ações que levem este público à aderirem às propostas governamentais de atendimento. Foi possível inferir que esta baixa adesão se dava em razão da incompatibilidade dos serviços oferecidos com a real necessidade de muitas destas pessoas, como por exemplo, os horários de atendimento e a falta de atividades com cunho educacional. Por isso, se faz necessário remodelar essa oferta de serviço público, com técnicos especializados e com uma estrutura de acordo com a demanda, de forma a atender as necessidades desses indivíduos.

Todas essas ações podem ser desempenhadas, em práticas de gestão, por um profissional da educação, que em razão de sua formação humanista tem possibilidades de desenvolvê-las a partir da perspectiva freireana da socioeducação, fazendo com que tais sujeitos (re) avaliem suas situações pessoais e consigam, a médio prazo, projetarem outras perspectivas de vida que não passem necessariamente pela continuidade na rua.

Também pode-se notar que o exercício de conscientização não diz respeito somente para a população em situação de rua, mas também para à sociedade civil organizada, que muitas vezes, desconhece essa realidade. Tal trabalho tem o intuito de manter o respeito, bom relacionamento e atenção com os que se encontram mais vulneráveis, de forma dupla, em que o indivíduo em situação de rua consiga planejar seu próprio futuro, percebendo a mudança de atitude social no sentido de acolhimento.

Sabe-se que todos os indivíduos são possuidores de direitos e devem ser tratados com igualdade, mesmo que suas realidades sejam diferentes. Diante do contexto social e da gravidade da situação específica dessas pessoas é preciso a implementação de políticas públicas capazes de ampliar a abrangência do Estado para com esse público, monitorando todas as ações, para que os projetos, programas e serviços tenham eficácia.

Essa experiência proporcionou o entendimento de que a Educação Popular de Rua como um direito deve ocorre de forma processual e contínua, e apresenta-se como uma possibilidade de execução de um serviço com maior eficácia para o público, trazendo-os para outras 
perspectivas de vida. Esta se dá com a harmonização aos direitos humanos, fundamentada nas propostas freireanas que asseguram a compreensão da realidade dos indivíduos e a mudança de uma perspectiva de vida melhor.

$\mathrm{Na}$ atuação do educador social, a conscientização e a libertação são ferramentas preponderantes, pois vislumbram uma emancipação ética, política e econômica, garantindo-se o direito essencial de dignidade humana. Sua abordagem é relevante: através do diálogo, consegue conhecer o nível de percepção de cada indivíduo, podendo a partir disto, realizar trabalhos que motivem a pessoa a sair das ruas. Este processo deve desafiar tais educandos a se inserirem em outros níveis do saber.

Portanto, conclui-se que o direito à educação pode fomentar a ressignificação de vida à população de rua, utilizando-se de projetos socioeducativos com o objetivo de criar referenciais positivos para a construção de (novas) identidades, fazendo com que os indivíduos se sintam novamente incluídos e pertencentes à sua sociedade.

\section{REFERÊNCIAS}

ALMEIDA, Sara Ferreira de. População em situação de rua e o retorno à educação escolar: entre dificuldades e possibilidades. In: Congresso Internacional de Pedagogia Social, p. 14; 2012, São Paulo. Proceedings online. Associação Brasileira de Educadores Sociais. Disponível em: <http://www.proceedings.scielo.br/scielo.php? script=sci_arttext\&pid=MSC0000000092012000200030\&lng=en\&nr m=abn>. Acesso em: 20 de abril de 2017.

BRAGA, Tiago Farias. O Território da Cracolândia: "Um novoantigo" calcanhar de Aquiles do Centro de Governador Valadares. Dissertação de mestrado em Gestão Integrada do Território. Universidade Vale do Rio Doce. Governador Valadares - MG. 2015.

BRANDÃO, Carlos Rodrigues. O que é Educação Popular. São Paulo: Brasiliense, 2006. 
BORTOLIM, Sérgio da Costa. A política educacional como instrumento da cidadania. Revista Acadêmica, 2014, n. 14, p. 143-155.

BRASIL. Constituição da República Federativa do Brasil. Senado Federal. Brasília.1988.

Decreto $n^{0}$. 7.053, de 23 de dezembro de 2009. Institui a Política Nacional para a População em Situação de Rua e seu Comitê Intersetorial de Acompanhamento e Monitoramento, e dá outras providências. Senado Federal. Brasília.1988.

Lei $n^{\circ}$ 9394, de 20 de dezembro de 1996. Estabelece as diretrizes e bases da Educação Nacional. Senado Federal. Brasília.1996.

. Lei $\mathbf{n}^{0} \mathbf{1 1 . 2 5 8}$, de 30 de dezembro de 2005. Dispõe sobre a organização da Assistência Social. Senado Federal. Brasília. 2005.

Orientações Técnicas: Centro de Referência Especializado para População em Situação de Rua - Centro Pop SUAS e População em Situação de Rua. Ministério do Desenvolvimento Social e Combate à Fome. Brasília. 2005.

. Portaria $n^{\circ} 843$ de 28 de dezembro de 2010. Dispõe sobre o cofinanciamento federal, por meio do Piso Fixo de Média Complexidade - PFMC, dos serviços socioassistenciais ofertados pelos Centros de Referência Especializados de Assistência Social - CREAS e pelos Centros de Referência Especializados para População em Situação de Rua, e dá outras providências. Ministério do Desenvolvimento Social e Combate à Fome. Brasília. 2010.

. Resolução n 109, de 11 de novembro de 2009. Tipificação Nacional de Serviços Socioassistenciais. Conselho Nacional de Assistência Social. Ministério de Desenvolvimento Social e Combate à Fome. Brasília. 2009.

COSTA, Ana Paula Motta. População em situação de rua: contextualização e caracterização. Revista Virtual Textos \& Contextos, $\mathrm{n}^{\circ} 4$, ano IV, dez. 2005. 
FREIRE, Paulo. FAUNDEZ, Antônio. Por uma pedagogia da pergunta. 5 ed. Rio de Janeiro: Paz e Terra, 2002.

In: FREIRE, Ana Maria Araújo (org.). Pedagogia da tolerância. São Paulo: Editora UNESP, 2005.

Ação cultural para a liberdade. $2^{\mathrm{a}}$ edição. Rio de Janeiro: Paz e Terra. 1977

- Pedagogia da autonomia: saberes necessários à prática educativa - 45a edição - Rio de Janeiro: Paz e Terra, 2013.

- Pedagogia da esperança: um reencontro com a pedagogia do oprimido. 5 ed. Rio de Janeiro: Paz e Terra, 1996.

Pedagogia da Indignação: Cartas Pedagógicas e Outros Escritos. São Paulo: Editora UNESP, 2000.

GALEANO, Eduardo. Veias continuam abertas na América Latina. Entrevista concedida a Mario Augusto Jakobskind. 2009. Disponível em: <www.outerspace.com.br>. Acesso em 21 de abril de 2017.

GOHN, Maria da Gloria. Educação não-formal e cultura política: impactos sobre o associativismo do terceiro setor. São Paulo, Cortez, 2004.

GOVERNADOR VALADARES. Secretaria Municipal de Assistência Social. Diagnostico da população de Governador Valadares em situação de rua. CAETANO, Cristina Salles; FERNANDES, Simone Maria; COSTA, Zilá Raquel Pereira. Governador Valadares, dez. de 2016.

HALL, Stuart. Identidade cultural na pós-modernidade. Rio de Janeiro: DP\&A, 2004.

MACHADO, Thayse. População em situação de rua e sociedade: Uma relação marcada por preconceito e estigma. 2014. $78 \mathrm{f}$. Trabalho de Conclusão de Curso (Graduação) - Faculdade de Serviço Social, Universidade Federal de Santa Catarina, Florianópolis, 2014. 
MARX, Karl. O capital. Trad. Reginaldo Sant'anna. Rio de Janeiro: Civilização Brasileira, 1988

ONU. Declaração Universal dos Direitos Humanos. 1948.

PAIVA, Jacyara Silva de. Epistemologia da educação social de rua. In: III I Congresso Internacional de Pedagogia Social, p. 3; 2010, São Paulo. Proceedings online. Associação Brasileira de Educadores Sociais. Disponível em:http://www.proceedings.scielo.br/scielo. php?script=sci_arttext\&pid=MSC0000000092010000100015\&Ing=en \&nrm=abn>. Acesso em: 21 de abril de 2017.

PEREIRA, Tatiana; SANTOS, Paula. Os serviços da Proteção Social Especial de Média Complexidade e o processo de construção de saída da rua. In: Portal Social, p. 6; 2013, Recife. Disponível em: <http:// www.proceedings.scielo.br/scielo.php?script=sci_arttext\&pid=MSC00000 00092010000100015\&lng=en\&nrm=abn>. Acesso em: 21 de abril de 2017.

PETRUS, Romans, Mercé. Profissão: Educador Social. Mercé Romans, Antoni Petrus, Jaume Trilla, trad. Ernani Rosa. Porto Alegre: Artimed, 2003.

PINEL, Hiran; COLODETE, Paulo Roque; PAIVA, Jacyara Silva. Pedagogia Social: definições, formação, espaços de trabalho, grandes nomes e epistemologias. Revista Conhecimento em Destaque. Serra. ES, v. 01, n. 02, jul/dez. 2012.

PINI, Francisca Rodrigues de Oliveira. Educação popular e os seus diferentes espaços: educação social de rua, prisional e campo. Campinas, dez. de 2006.

VELHO, Gilberto. Projeto e Metamorfose - Antropologia das Sociedades Complexas. 3ed. Rio de Janeiro: Jorge Zahar, 2003.

VIEIRA, Maria. População de rua: quem é? Como vive? Como é vista? São Paulo: Hucitec, 1992. 